\title{
Study on the Impact of Thermal Agitation on Doppler Coefficient in Epithermal Range for Gd-Bearing Fuel
}

\author{
Satoshi Takeda, ${ }^{1,2}$ Satoshi Ino, ${ }^{1}$ Kazuhiro Wada, ${ }^{1}$ Michitaka Ono, ${ }^{1}$ and Takanori Kitada ${ }^{1}$ \\ ${ }^{1}$ Division of Sustainable Energy and Environmental Engineering, Graduate School of Engineering, Osaka University, 2-1 Yamadaoka, \\ Suita-shi, Osaka 565-0871, Japan \\ ${ }^{2}$ Fuel Engineering and Development Department, Kumatori Works, Nuclear Fuel Industries, Ltd., 950 Asashiro-nishi 1-chome, \\ Kumatori-cho, Sennan-gun, Osaka 590-0481, Japan \\ Correspondence should be addressed to Satoshi Takeda; s-takeda@ne.see.eng.osaka-u.ac.jp
}

Received 15 November 2015; Revised 20 December 2015; Accepted 20 December 2015

Academic Editor: Arkady Serikov

Copyright ( $\odot 2016$ Satoshi Takeda et al. This is an open access article distributed under the Creative Commons Attribution License, which permits unrestricted use, distribution, and reproduction in any medium, provided the original work is properly cited.

The impact of thermal agitation on Doppler coefficient for Gd-bearing fuel was analyzed. It was found through the analysis that the impact increases when a small amount of $\mathrm{Gd}_{2} \mathrm{O}_{3}$ is added to pure $\mathrm{UO}_{2}$ fuel although the impact decreases for a large amount of $\mathrm{Gd}_{2} \mathrm{O}_{3}$. This tendency was discussed with the usage of simplified expression for the difference of Doppler coefficient. The simplified expression was used to consider the tendency, and it was revealed that the tendency mainly comes from the rapid decrement of multiplication factor and the relatively slow decrement of the magnitude of sensitivity coefficient of U-238 capture cross section at low $\mathrm{Gd}_{2} \mathrm{O}_{3}$ concentration. Similar tendency which shows a maximum impact on Doppler coefficient at interior concentration is expected for other $\mathrm{UO}_{2}$ fuel with a slight content of strong absorber. This indicates that Doppler coefficient of $\mathrm{UO}_{2}$ fuel system with low content of strong absorber should be analyzed carefully by considering thermal agitation in epithermal range.

\section{Introduction}

Scattering kernel used in epithermal range is usually treated as the asymptotic model in solving the slowing down equation, which does not take thermal agitation into account. If the targets are scatterings of light isotopes, the asymptotic model is appropriate since the change of scattering kernel by thermal agitation is trivial. But for heavy isotopes, the asymptotic model is not appropriate for scattering kernel especially in epithermal range [1] where Doppler effect is remarkable in thermal reactor. Therefore, the impact of thermal agitation on Doppler coefficient has been investigated by many researchers [2-5]. And a simplified treatment of the exact scattering model for deterministic slowing down equation was also developed to reduce the huge computational cost. This simplified treatment called Upscattering Approximation (UA) method [6] was applied to GROUPR module of the NJOY [7] system and was verified through the comparison of impact on Doppler coefficient with other reported calculation results [6].

Many evaluations were performed by many researchers but the target composition to evaluate Doppler coefficient is mainly $\mathrm{UO}_{2}$ without any poison. As easily expected, the addition of poison such as $\mathrm{Gd}_{2} \mathrm{O}_{3}$ to $\mathrm{UO}_{2}$ fuel causes the change in multiplication factor and also causes the change in Doppler coefficient by the increment of capture rate of the poison. Thus, it is expected that the impact of thermal agitation on Doppler coefficient varies as a function of poison content in $\mathrm{UO}_{2}$ fuel.

The purpose of this paper is to evaluate the impact of thermal agitation on the Doppler coefficient for Gd-bearing fuel and to reveal the mechanism of the impact of thermal agitation on Doppler coefficient in Gd-bearing fuel. Section 2 deals with the evaluation of the impact for Gd-bearing fuel for various $\mathrm{Gd}_{2} \mathrm{O}_{3}$ concentrations. Section 3 shows detailed calculation results to describe the dependence of the impact 


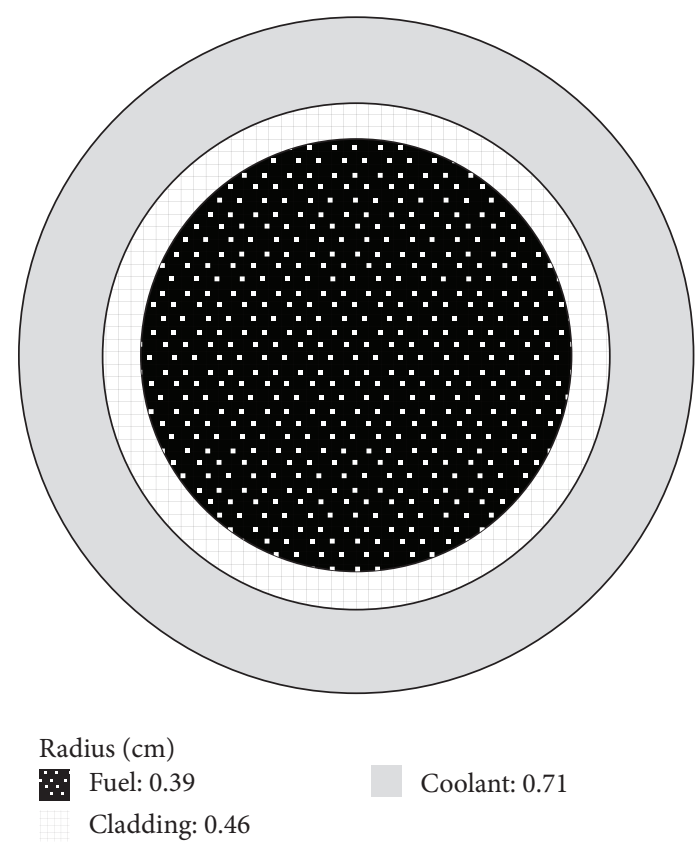

Figure 1: Pin cell model.

on $\mathrm{Gd}_{2} \mathrm{O}_{3}$ concentration. Discussions and conclusions are summarized in Sections 4 and 5, respectively.

\section{Calculation of Impact of Thermal Agitation on Doppler Coefficient}

The calculation procedure and the calculation results are described in this chapter.

2.1. Calculation Procedure. The calculation geometry is modeled from conventional PWR cell for $4.8 \mathrm{wt} \%$ enriched $\mathrm{UO}_{2}$ fuel with $\mathrm{Gd}_{2} \mathrm{O}_{3}$ as shown in Figure 1 and Table 1. Fuel temperature is changed from 600 to $900 \mathrm{~K}$ and cladding and coolant temperature are unchanged to evaluate Doppler coefficient.

The Doppler reactivity is calculated from two multiplication factors of different fuel temperatures as

$$
\text { D. } C_{\text {method }}=\frac{\left(1 / k_{\text {low,method }}-1 / k_{\text {high,method }}\right)}{\Delta T} \text {, }
$$

method = asymptotic model, exact model,

where $k_{\text {low }}$ and $k_{\text {high }}$ are multiplication factors calculated at low temperature and high temperature, respectively, and $\Delta T$ shows the difference between low and high temperatures. The impact of Doppler coefficient is obtained as the relative difference of Doppler coefficient between asymptotic model and exact scattering model.

2.2. Calculation Results. The calculation is performed by continuous energy Monte Carlo code MVP which can handle thermal agitation in epithermal range [8] with JENDL-4.0
TABLE 1: Calculation conditions.

\begin{tabular}{ll}
\hline Fuel & \\
Material & $\mathrm{UO}_{2}$ with $\mathrm{Gd}_{2} \mathrm{O}_{3}$ \\
$\mathrm{U}-235$ enrichment & $4.8 \mathrm{wt} \%$ \\
$\mathrm{Gd}_{2} \mathrm{O}_{3}$ concentration & $0 \sim 20 \mathrm{wt} \%$ using following Gd \\
& vector \\
& $\mathrm{Gd}-152: 0.2 \mathrm{wt} \%$ \\
& $\mathrm{Gd}-154: 2.2 \mathrm{wt} \%$ \\
& $\mathrm{Gd}-155: 14.8 \mathrm{wt} \%$ \\
& $\mathrm{Gd}-156: 20.5 \mathrm{wt} \%$ \\
& $\mathrm{Gd}-157: 15.6 \mathrm{wt} \%$ \\
& $\mathrm{Gd}-158: 24.8 \mathrm{wt} \%$ \\
Gemperature & $600 \mathrm{~K}, 900 \mathrm{~K}$ \\
\hline Cladding & \\
Material & Zircalloy- 4 \\
Temperature & $600 \mathrm{~K}$ \\
\hline Coolant & \\
Material & $\mathrm{H}_{2} \mathrm{O}$ \\
Temperature & $600 \mathrm{~K}$ \\
\hline Boundary condition & White reflection \\
\hline
\end{tabular}

TABLE 2: Impact evaluated by MVP for various $\mathrm{Gd}_{2} \mathrm{O}_{3}$ concentrations.

\begin{tabular}{lccc}
\hline $\begin{array}{l}\mathrm{Gd}_{2} \mathrm{O}_{3} \\
\text { concentration } \\
{[\mathrm{wt} \%]}\end{array}$ & $\begin{array}{c}\text { Impact on } \\
\text { Doppler } \\
\text { coefficient [\%] }\end{array}$ & Error [\%1 $\sigma]$ \\
\hline 0 & 8.1 & \pm & 0.3 \\
0.2 & 10.6 & \pm & 0.5 \\
2 & 9.9 & \pm & 0.7 \\
5 & 8.9 & \pm & 0.7 \\
10 & 7.7 & \pm & 0.7 \\
20 & 5.6 & \pm & 0.7 \\
\hline
\end{tabular}

library [9]. The impact calculated by $10^{9}$ histories is summarized in Table 2. Table 2 shows that the impact increases by adding small amount of $\mathrm{Gd}_{2} \mathrm{O}_{3}$ to pure $\mathrm{UO}_{2}$ fuel and the impact decreases by adding large amount of $\mathrm{Gd}_{2} \mathrm{O}_{3}(10 \sim$ $20 \mathrm{wt} \%)$. The smaller impact at high $\mathrm{Gd}_{2} \mathrm{O}_{3}$ concentration can be explained by smaller amount of U-238 which is the main isotope to cause Doppler reactivity. On the other hand, the impact at low $\mathrm{Gd}_{2} \mathrm{O}_{3}$ concentration may be enhanced compared to that at pure $\mathrm{UO}_{2}$ case. Further evaluation is necessary to reveal the mechanism of the enhanced impact at low $\mathrm{Gd}_{2} \mathrm{O}_{3}$ concentration, but detailed evaluation was performed by deterministic method to reveal the mechanism because the statistical error by stochastic method will bring the ambiguity to consider the mechanism.

\section{Detailed Evaluation of Impact}

The calculation process and the calculation results for detailed evaluation of the impact are described in this chapter. 
TABLE 3: Impact evaluated by UA method for various $\mathrm{Gd}_{2} \mathrm{O}_{3}$ concentrations.

\begin{tabular}{lc}
\hline $\mathrm{Gd}_{2} \mathrm{O}_{3}$ concentration [wt\%] & $\begin{array}{c}\text { Impact on Doppler } \\
\text { coefficient [\%] }\end{array}$ \\
\hline 0 & 9.4 \\
0.2 & 12.2 \\
2 & 12.0 \\
5 & 10.6 \\
10 & 8.5 \\
20 & 5.6 \\
\hline
\end{tabular}

3.1. Calculation Process. Calculation geometry and calculation conditions are the same as previous chapter. Deterministic evaluations of Doppler coefficient with considering thermal agitation were performed by the following process. The multiplication factor with considering thermal agitation is evaluated with the usage of sensitivity coefficients for the multiplication factor and the relative difference of cross sections between asymptotic model and exact model as expressed in

$$
k_{\mathrm{UA}}=k_{\mathrm{conv}} \cdot\left(1+\sum_{g} d^{g} \cdot S^{g}\right)
$$

where $k_{\text {conv }}$ is a multiplication factor calculated by SRAC2006 [10] based on asymptotic model and $g$ is the suffix of energy group and $S^{g}$ is the sensitivity coefficient for multiplication factor calculated by SRAC2006 and SAINT-II [11] system and $d^{g}$ is calculated as the relative difference of cross section between asymptotic model and UA method evaluated by NJOY with ENDF-B/VII.0 [12]. Here the exact model is replaced as UA method which has developed and verified to evaluate the cross section with considering thermal agitation for various fuel compositions [6]. The sensitivity coefficient $S^{g}$ is defined as the ratio of relative change of multiplication factor to the relative change of cross section. Thereby the sensitivity coefficient is expressed as

$$
S^{g}=\frac{d k / k}{d \sigma^{g} / \sigma^{g}}
$$

where $\sigma^{g}$ is group-averaged cross section of energy group $g$. The impact of thermal agitation on Doppler coefficient was evaluated by using the multiplication factors of conventional calculations without considering thermal agitation and those calculated by (2) for considering thermal agitation.

The technique shown in this section is useful to obtain breakdown in isotopes, reaction types, and energy group because each of the parameters is evaluated separately.

3.2. Calculation Results. The impact on Doppler coefficient is summarized in Table 3 . Table 3 shows that the impact on Doppler coefficient is small at high $\mathrm{Gd}_{2} \mathrm{O}_{3}$ concentration and the impact is enhanced at low $\mathrm{Gd}_{2} \mathrm{O}_{3}$ concentration, as also shown in Table 2 where the results were obtained by Monte Carlo calculations. There are some differences in magnitude between Tables 2 and 3, but the tendency of the impact

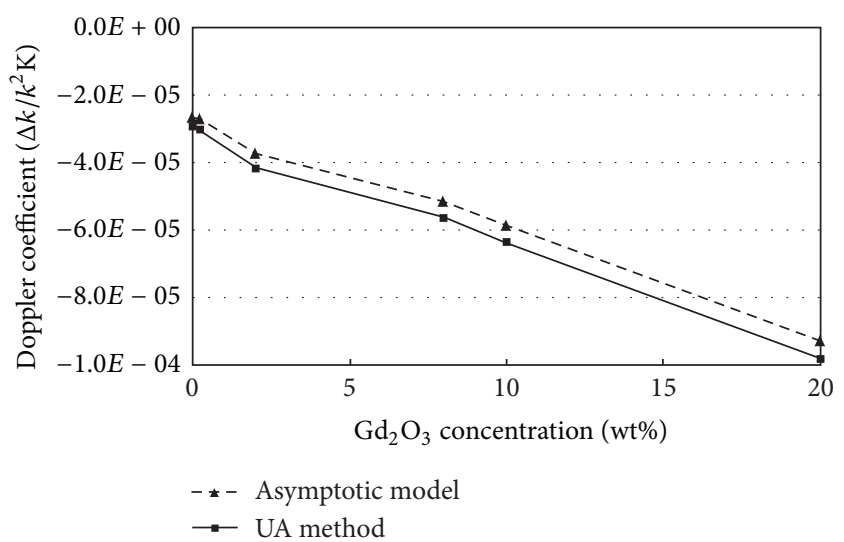

Figure 2: Comparison of Doppler coefficient.

is the same. Therefore further considerations were carried out to reveal the mechanism of the tendency especially to reveal the factor to cause the enhanced impact at low $\mathrm{Gd}_{2} \mathrm{O}_{3}$ concentration.

Doppler coefficients calculated by conventional asymptotic kernel model and UA method are shown in Figure 2. Figure 2 shows that the magnitude of Doppler coefficient becomes large monotonically and linearly according to the increment of $\mathrm{Gd}_{2} \mathrm{O}_{3}$ concentration.

Table 4 presents the nuclide and reaction breakdown of the impact on Doppler coefficient. Another breakdown by energy range is summarized in Table 5. As shown in Tables 4 and 5, U-238 capture reaction is the dominant cause of the impact of thermal agitation on Doppler coefficient, and the impact is remarkable at the energy around 21,37 , and $66 \mathrm{eV}$ as already reported in the literature [2-5]. In addition to this, the impact of thermal agitation on Doppler coefficient depends on $\mathrm{Gd}_{2} \mathrm{O}_{3}$ concentration and the impact increases at low $\mathrm{Gd}_{2} \mathrm{O}_{3}$ concentration compared to pure $\mathrm{UO}_{2}$ fuel as shown in Tables 4 and 5.

\section{Discussions}

The impact of thermal agitation on Doppler coefficient increases up to about $12 \%$ when $\mathrm{Gd}_{2} \mathrm{O}_{3}$ concentration is around $0.2 \mathrm{wt} \%$ and $2 \mathrm{wt} \%$ and the impact decreases according to the increment of $\mathrm{Gd}_{2} \mathrm{O}_{3}$ concentration although $\mathrm{Gd}$ isotopes do not have the impact of thermal agitation on Doppler coefficient as shown in Table 4.

In order to discuss this tendency, a simplified expression of the difference in Doppler coefficient is derived in Section 4.1 for detailed consideration of the mechanism. Section 4.2 shows the numerical results by using the simplified expression and the discussion of the mechanism especially to cause the enhanced impact at low $\mathrm{Gd}_{2} \mathrm{O}_{3}$ concentration.

4.1. Derivation of Simplified Expression. In this section, the impact on Doppler coefficient $(\Delta D$ D.C) caused by thermal agitation is expressed in simple expression for easy consideration to reveal the mechanism. 
TABLE 4: Nuclide and reaction breakdown of impact on the Doppler coefficient of Gd-bearing fuel.

\begin{tabular}{|c|c|c|c|c|c|c|}
\hline \multirow{2}{*}{ Nuclide reaction } & \multicolumn{6}{|c|}{$\mathrm{Gd}_{2} \mathrm{O}_{3}$ concentration [wt $\%$ ] } \\
\hline & 0 & 0.2 & 2 & 5 & 10 & 20 \\
\hline U-238 capture & $9.4 \%$ & $12.2 \%$ & $12.0 \%$ & $10.6 \%$ & $8.4 \%$ & $5.4 \%$ \\
\hline U-235 capture & $0.0 \%$ & $0.0 \%$ & $0.0 \%$ & $0.0 \%$ & $0.0 \%$ & $0.0 \%$ \\
\hline Gd-155 capture & - & $0.0 \%$ & $0.0 \%$ & $0.0 \%$ & $0.0 \%$ & $0.0 \%$ \\
\hline Gd-156 capture & - & $0.0 \%$ & $0.0 \%$ & $0.0 \%$ & $0.0 \%$ & $0.1 \%$ \\
\hline Gd-157 capture & - & $0.0 \%$ & $0.0 \%$ & $0.0 \%$ & $0.1 \%$ & $0.1 \%$ \\
\hline Gd-158 capture & - & $0.0 \%$ & $0.0 \%$ & $0.0 \%$ & $0.0 \%$ & $0.0 \%$ \\
\hline All & $9.4 \%$ & $12.2 \%$ & $12.0 \%$ & $10.6 \%$ & $8.5 \%$ & $5.6 \%$ \\
\hline
\end{tabular}

TABLE 5: Energy breakdown of impact on the Doppler coefficient of Gd-bearing fuel.

\begin{tabular}{|c|c|c|c|c|c|c|}
\hline \multirow{2}{*}{ Energy range $[\mathrm{eV}]$} & \multicolumn{6}{|c|}{$\mathrm{Gd}_{2} \mathrm{O}_{3}$ concentration $[\mathrm{wt} \%]$} \\
\hline & 0 & 0.2 & 2 & 5 & 10 & 20 \\
\hline $3.93 \sim 5.04$ & $0.0 \%$ & $0.0 \%$ & $0.0 \%$ & $0.0 \%$ & $0.0 \%$ & $0.0 \%$ \\
\hline $5.04 \sim 6.48$ & $-0.1 \%$ & $-0.2 \%$ & $-0.1 \%$ & $-0.1 \%$ & $-0.1 \%$ & $0.0 \%$ \\
\hline $6.48 \sim 8.32$ & $0.9 \%$ & $1.1 \%$ & $0.8 \%$ & $0.7 \%$ & $0.4 \%$ & $0.2 \%$ \\
\hline $8.32 \sim 10.68$ & $0.0 \%$ & $0.0 \%$ & $0.0 \%$ & $0.0 \%$ & $0.0 \%$ & $0.0 \%$ \\
\hline $10.68 \sim 13.71$ & $0.0 \%$ & $0.0 \%$ & $0.0 \%$ & $0.0 \%$ & $0.0 \%$ & $0.0 \%$ \\
\hline $13.71 \sim 17.60$ & $0.0 \%$ & $0.0 \%$ & $0.0 \%$ & $0.0 \%$ & $0.1 \%$ & $0.1 \%$ \\
\hline $17.60 \sim 22.60$ & $2.1 \%$ & $2.7 \%$ & $2.6 \%$ & $2.2 \%$ & $1.7 \%$ & $1.0 \%$ \\
\hline $22.60 \sim 29.02$ & $0.0 \%$ & $0.0 \%$ & $0.0 \%$ & $0.0 \%$ & $0.0 \%$ & $0.0 \%$ \\
\hline $29.02 \sim 37.27$ & $4.6 \%$ & $6.1 \%$ & $6.2 \%$ & $5.6 \%$ & $4.6 \%$ & $3.1 \%$ \\
\hline $37.27 \sim 47.85$ & $-0.2 \%$ & $-0.2 \%$ & $-0.2 \%$ & $-0.2 \%$ & $-0.2 \%$ & $-0.1 \%$ \\
\hline $47.85 \sim 61.44$ & $0.0 \%$ & $0.0 \%$ & $0.0 \%$ & $0.0 \%$ & $0.0 \%$ & $0.0 \%$ \\
\hline $61.44 \sim 78.89$ & $1.4 \%$ & $1.8 \%$ & $1.8 \%$ & $1.6 \%$ & $1.3 \%$ & $0.8 \%$ \\
\hline 78.89 101.3 & $0.0 \%$ & $-0.1 \%$ & $0.0 \%$ & $0.0 \%$ & $0.0 \%$ & $0.0 \%$ \\
\hline 101.3 130.1 & $0.7 \%$ & $1.0 \%$ & $0.9 \%$ & $0.8 \%$ & $0.7 \%$ & $0.5 \%$ \\
\hline All & $9.4 \%$ & $12.2 \%$ & $12.0 \%$ & $10.6 \%$ & $8.5 \%$ & $5.6 \%$ \\
\hline
\end{tabular}

The impact of Doppler coefficient by thermal agitation at energy group $g$ only is expressed as

$$
\begin{aligned}
\Delta \mathrm{D} . \mathrm{C}^{g} & =\frac{\left\{\left(1 / k_{\text {low,UA }}^{g}-1 / k_{\text {high,UA }}^{g}\right)-\left(1 / k_{\text {low,conv }}-1 / k_{\text {high,conv }}\right)\right\}}{\Delta T} \\
& =\frac{\left\{\left(\left(k_{\text {low,conv }}-k_{\text {low,UA }}^{g}\right) / k_{\text {low,UA }}^{g} k_{\text {low,conv }}\right)-\left(\left(k_{\text {high,conv }}-k_{\text {high,UA }}^{g}\right) / k_{\text {high,UA }}^{g} k_{\text {high,conv }}\right)\right\}}{\Delta T},
\end{aligned}
$$

where $k_{\mathrm{UA}}^{g}$ is a multiplication factor which treats thermal agitation effect at energy group $g$ and calculated by $k_{\mathrm{UA}}^{g}=$ $k_{\text {conv }} \cdot\left(1+d^{g} \cdot S^{g}\right)$ as easily expected from (2). Therefore, (4) can be transformed as

$$
\begin{aligned}
& \Delta \mathrm{D} . \mathrm{C}^{g} \\
& =\frac{\left\{\left(-d_{\text {low }}^{g} S_{\text {low }}^{g} / k_{\text {low,UA }}^{g}\right)-\left(-d_{\text {high }}^{g} S_{\text {high }}^{g} / k_{\text {high, UA }}^{g}\right)\right\}}{\Delta T} .
\end{aligned}
$$

The change of $S^{g}$ by the change of temperature is not remarkable compared to the other parameters as shown in later sections (Figure 4). Thus, the sensitivity coefficient can be approximated as

$$
S^{\mathcal{g}} \cong S_{\text {low }}^{g} \cong S_{\text {high }}^{g} .
$$

Then, (5) can be transformed as

$$
\Delta \mathrm{D} . \mathrm{C}^{g} \cong \frac{S^{g}\left(d_{\mathrm{high}}^{g} / k_{\mathrm{high}, \mathrm{UA}}^{g}-d_{\mathrm{low}}^{g} / k_{\mathrm{low}, \mathrm{UA}}^{g}\right)}{\Delta T} .
$$

For further simplification of (7), following approximations are considered.

The capture cross section of Gd nuclide is remarkably large at thermal range, but the magnitude is not so large 


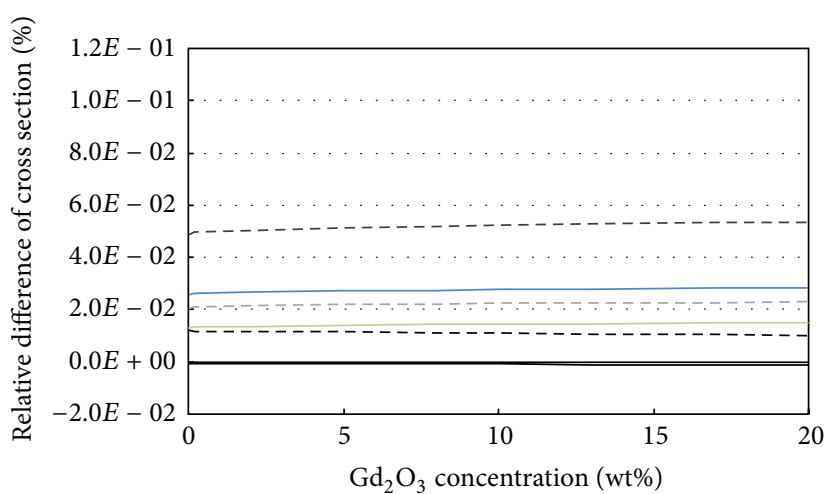

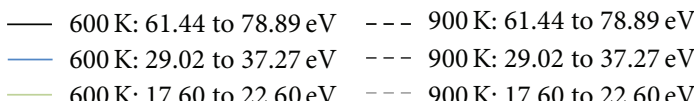

FIGURE 3: Relative difference of U-238 capture cross section.

compared to that of U-238 at the energy group where the agitation effect is sensitive to Doppler coefficient. Thus, $d^{g}$ of $\mathrm{U}-238$ does not strongly depend on $\mathrm{Gd}_{2} \mathrm{O}_{3}$ concentration at the energy group and the difference of $d^{g}$ is nearly independent of $\mathrm{Gd}_{2} \mathrm{O}_{3}$ concentration as shown in Figure 3. Therefore, new parameter $A^{g}$ can be set as independent parameter of $\mathrm{Gd}_{2} \mathrm{O}_{3}$ concentration as

$$
A^{g} \cong d_{\text {high }}^{g}-d_{\text {low }}^{g} .
$$

By using (8), (7) is transformed as

$$
\begin{aligned}
& \Delta \mathrm{D} \cdot \mathrm{C}^{g} \cong \frac{S^{g}\left(\left(A^{g}+d_{\text {low }}^{g}\right) / k_{\text {high, } \mathrm{UA}}^{g}-d_{\text {low }}^{g} / k_{\text {low, }, \mathrm{UA}}^{g}\right)}{\Delta T} \\
& =\frac{S^{g}\left(\left(d_{\text {low }}^{g}\left(k_{\text {low }, \mathrm{UA}}^{g}-k_{\text {high, } \mathrm{UA}}^{g}\right)+A^{g} k_{\text {low, } \mathrm{UA}}^{g}\right) / k_{\text {high, } \mathrm{UA}}^{g} k_{\text {low }, \mathrm{UA}}^{g}\right)}{\Delta T} .
\end{aligned}
$$

Practically, $\left(k_{\text {high,UA }}^{g}-k_{\text {low,UA }}^{g}\right)$ is quite small compared to $k_{\text {low,UA }}^{g}$ in the evaluation of the difference in Doppler coefficient. Therefore, (9) can be simplified by neglecting $\left(k_{\text {high,UA }}^{g}-\right.$ $\left.k_{\text {low, UA }}^{g}\right)$ to obtain

$$
\Delta \mathrm{D} . \mathrm{C}^{g} \cong \frac{A^{g}\left(S^{g} / k_{\text {high,UA }}^{g}\right)}{\Delta T} .
$$

Equation (10) shows that the difference in Doppler coefficient as a function of $\mathrm{Gd}_{2} \mathrm{O}_{3}$ concentration can be simply discussed as the product of the sensitivity coefficient and the inverse of multiplication factor.

4.2. Impact on Doppler Coefficient. In this section, the impact of thermal agitation on Doppler coefficient in epithermal range is discussed by using (10). The sensitivity coefficient $S^{g}$ of U-238 capture cross section to multiplication factor is shown in Figure 4. Figure 4 shows that the magnitude of $S^{g}$ decreases according to the increment of $\mathrm{Gd}_{2} \mathrm{O}_{3}$ concentration since the ratio of the capture reaction of $\mathrm{U}-238$ to total capture rate becomes small according to the increment of $\mathrm{Gd}_{2} \mathrm{O}_{3}$

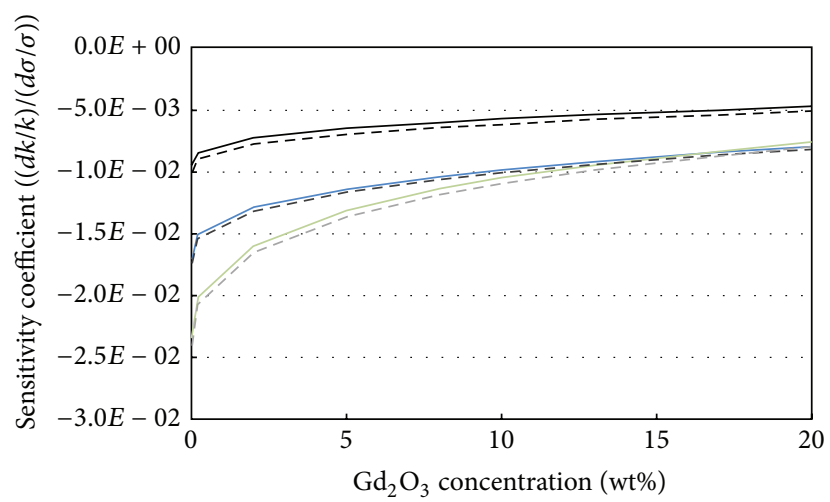

$\begin{array}{ccc}600 \mathrm{~K}: 61.44 \text { to } 78.89 \mathrm{eV} & ---900 \mathrm{~K}: 61.44 \text { to } 78.89 \mathrm{eV} \\ 600 \mathrm{~K}: 29.02 \text { to } 37.27 \mathrm{eV} & ---900 \mathrm{~K}: 29.02 \text { to } 37.27 \mathrm{eV} \\ 600 \mathrm{~K}: 17.60 \text { to } 22.60 \mathrm{eV} & ---900 \mathrm{~K}: 17.60 \text { to } 22.60 \mathrm{eV}\end{array}$

FIGURE 4: Sensitivity coefficient of U-238 capture cross section to multiplication factor.

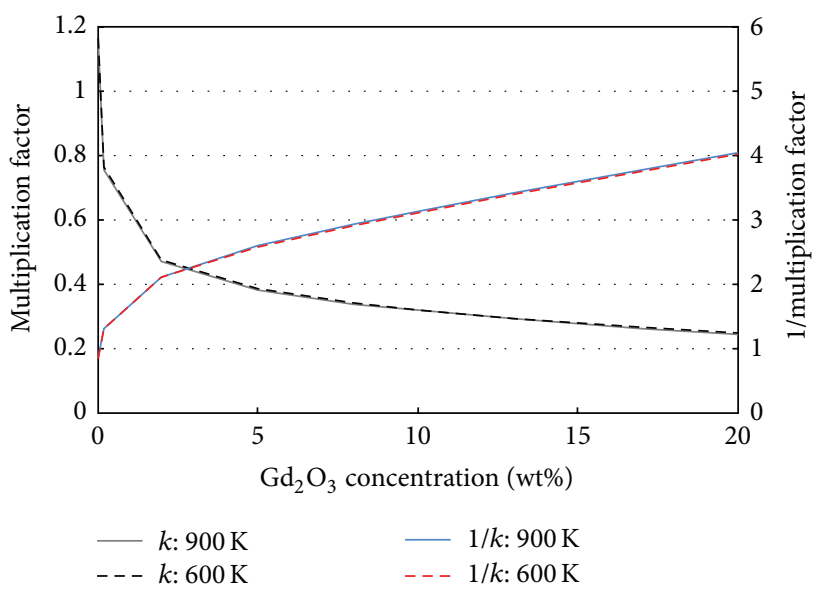

FIGURE 5: Multiplication factor and inverse of multiplication factor.

concentration. Figure 5 shows the multiplication factor and the inverse of the multiplication factor as a function of $\mathrm{Gd}_{2} \mathrm{O}_{3}$ concentration. Figure 5 shows that the inverse of multiplication factor increases monotonically by adding $\mathrm{Gd}_{2} \mathrm{O}_{3}$ because of its huge capture cross section. Figure 6 shows the difference in Doppler coefficient evaluated by exact solution and the simplified expression expressed as (10). Two evaluations shown in Figure 6 are almost the same, which shows the correctness of the simplified expression. Particular behavior of the impact as a function of $\mathrm{Gd}_{2} \mathrm{O}_{3}$ concentration can be interpreted by using the above mentioned results as follows.

As already described, there is a maximum impact of thermal agitation on Doppler coefficient at low $\mathrm{Gd}_{2} \mathrm{O}_{3}$ concentration and this tendency comes from the rapid increase of $1 / k$ and slow increase of the magnitude of Doppler coefficient at low $\mathrm{Gd}_{2} \mathrm{O}_{3}$ concentration as shown in Figures 2 and 5. In other words, the sensitivity coefficient in Figure 4 shows the decrement in magnitude according to the increment of $\mathrm{Gd}_{2} \mathrm{O}_{3}$ concentration because of the increment of $\mathrm{Gd}_{2} \mathrm{O}_{3}$ 


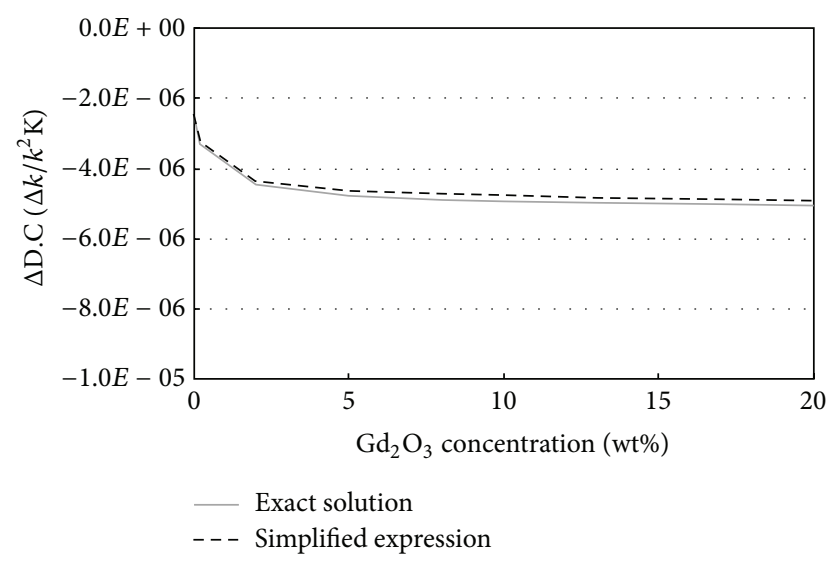

FiguRE 6: Difference in Doppler coefficient.

capture rate to total capture rate; on the other hand, the decrement of multiplication factor is remarkable especially at low $\mathrm{Gd}_{2} \mathrm{O}_{3}$ concentration as shown in Figure 5. And at high $\mathrm{Gd}_{2} \mathrm{O}_{3}$ concentration, the value of $\Delta$ D.C/D.C becomes small and is mainly caused by the fact that the magnitude of Doppler coefficient becomes huge although $\triangle$ D.C is almost constant as shown in Figures 2 and 6. This is the reason why there is a maximum point of the impact on Doppler coefficient for Gd-bearing fuel.

Similar tendency which shows a maximum impact is expected for the fuel with the slight content of strong absorber. Therefore, Doppler coefficient of the system which contains low content of strong absorber should be analyzed carefully with the consideration of thermal agitation.

\section{Conclusions}

The impact of thermal agitation on Doppler coefficient of Gdbearing fuel was analyzed. The results show that the impact increases by adding a small amount of $\mathrm{Gd}_{2} \mathrm{O}_{3}(\sim 2 \mathrm{wt} \%)$ to $\mathrm{UO}_{2}$ fuel, although the impact decreases by adding a large amount of $\mathrm{Gd}_{2} \mathrm{O}_{3}(\sim 10 \mathrm{wt} \%)$ to $\mathrm{UO}_{2}$ fuel. This tendency was analyzed with the usage of simplified expression of the difference in Doppler coefficient. The difference in Doppler coefficient varies as a function of $\mathrm{Gd}_{2} \mathrm{O}_{3}$ concentration, and this is mainly caused by the two factors: sensitivity coefficient of U-238 capture cross section to multiplication factor and multiplication factor. The magnitude of both factors decreases according to the increment of $\mathrm{Gd}_{2} \mathrm{O}_{3}$ concentration, but the decrement rate of multiplication factor is remarkable compared to that of the sensitivity coefficient at low $\mathrm{Gd}_{2} \mathrm{O}_{3}$ concentration, where the self-shielding of Gd isotopes is not so important and the content of $\mathrm{U}-238$ is roughly the same to the fuel without $\mathrm{Gd}_{2} \mathrm{O}_{3}$. The decrement rates of both factors are almost the same at high $\mathrm{Gd}_{2} \mathrm{O}_{3}$ concentration, which brings almost the same difference in Doppler coefficient between with and without considering thermal agitation. On the other hand, the magnitude of Doppler coefficient increases monotonically and linearly according to the increment of
$\mathrm{Gd}_{2} \mathrm{O}_{3}$ mainly caused by the decrement of multiplication factor. Therefore, there is a maximum point of the relative difference in Doppler coefficient caused by thermal agitation.

Similar tendency is expected for other strong-absorberbearing fuel. Thus, it should be noted that the Doppler coefficient of the fuel with a slight amount of strong absorber should be analyzed carefully with the consideration of thermal agitation.

\section{Conflict of Interests}

The authors declare that there is no conflict of interests regarding the publication of this paper.

\section{Acknowledgment}

The authors would like to thank Dr. Nagaya for his kind support for the evaluation by continuous energy Monte Carlo code MVP.

\section{References}

[1] M. Ouisloumer and R. Sanchez, "A model for neutron scattering off heavy isotopes that accounts for thermal agitation effects," Nuclear Science and Engineering, vol. 107, no. 3, pp. 189-200, 1991.

[2] R. Dagan, "On the use of $\mathrm{S}(\alpha, \beta)$ tables for nuclides with well pronounced resonances," Annals of Nuclear Energy, vol. 32, no. 4, pp. 367-377, 2005.

[3] B. Becker, R. Dagan, and C. H. M. Broders, "An alternative stochastic doppler broadening algorithm," in Proceedings of the International Conference on Mathematics, Computational Methods \& Reactor Physics (MぬC '09), Saratoga Springs, NY, USA, May 2009.

[4] T. Mori and Y. Nagaya, "Comparison of resonance elastic scattering models newly implemented in MVP continuous-energy monte carlo code," Journal of Nuclear Science and Technology, vol. 46, no. 8, pp. 793-798, 2009.

[5] D. Lee, K. Smith, and J. Rhodes, "The impact of ${ }^{238} \mathrm{U}$ resonance elastic scattering approximations on thermal reactor Doppler reactivity," Annals of Nuclear Energy, vol. 36, no. 3, pp. 274-280, 2009.

[6] M. Ono, K. Wada, and T. Kitada, "Simplified treatment of exact resonance elastic scattering model in deterministic slowing down equation," in Proceedings of the International Conference on the Physics of Reactors 2012: Advances in Reactor Physics (PHYSOR '12), pp. 2625-2636, Knoxville, Tenn, USA, April 2012.

[7] R. E. MacFarlane and D. W. Muir, "NJOY99.0 code system for producing pointwise and multigroup neutron and photon cross sections from ENDF/B data," Tech. Rep. PSR-480/NJOY99.00, Los Alamos National Laboratory, 2000.

[8] Y. Nagaya, Private Communication, JAEA, Ibaraki, Japan, 2014.

[9] K. Shibata, O. Iwamoto, T. Nakagawa et al., "JENDL-4.0: a new library for nuclear science and engineering," Journal of Nuclear Science and Technology, vol. 48, no. 1, pp. 1-30, 2011.

[10] K. Okumura, T. Kugo, K. Kaneko, and K. Tsuchihashi, "SRAC2006: a comprehensive neutronics calculation code system," JAEA-Data/Code 2007-004, 2007. 
[11] M. Nakano, T. Takeda, and H. Takano, "Sensitivity analysis of cell neutronic parameters in high-conversion light-water reactors," Journal of Nuclear Science and Technology, vol. 24, no. 8, pp. 610-620, 1987.

[12] M. B. Chadwick, P. Obložinský, M. Herman et al., "ENDF/BVII.0: next generation evaluated nuclear data library for nuclear science and technology," Nuclear Data Sheets, vol. 107, no. 12, pp. 2931-3060, 2006. 

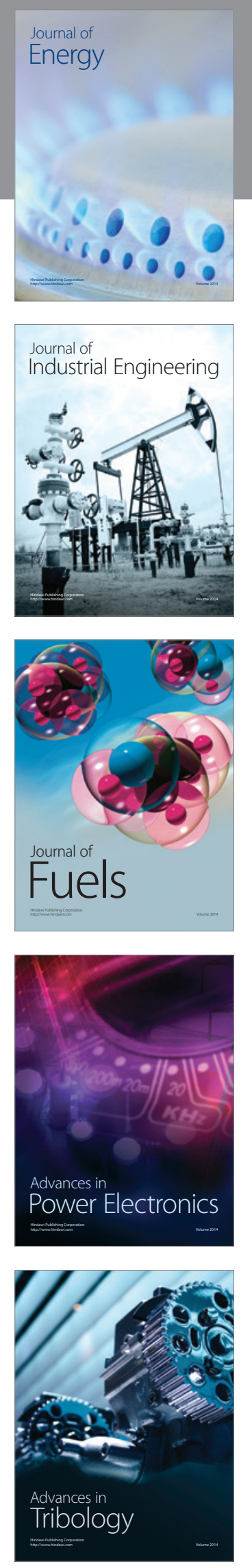
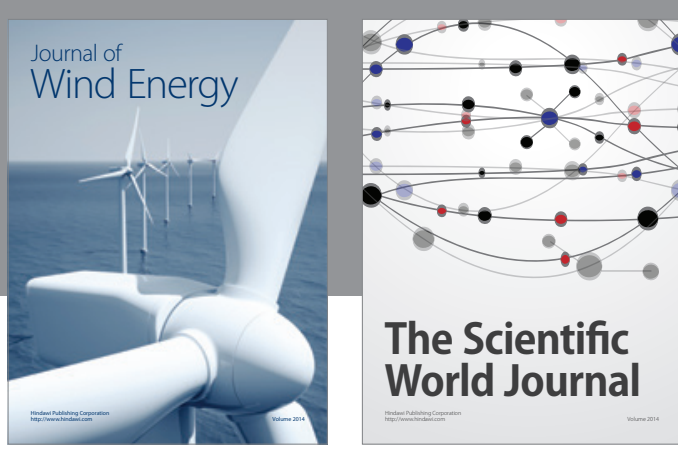

The Scientific World Journal
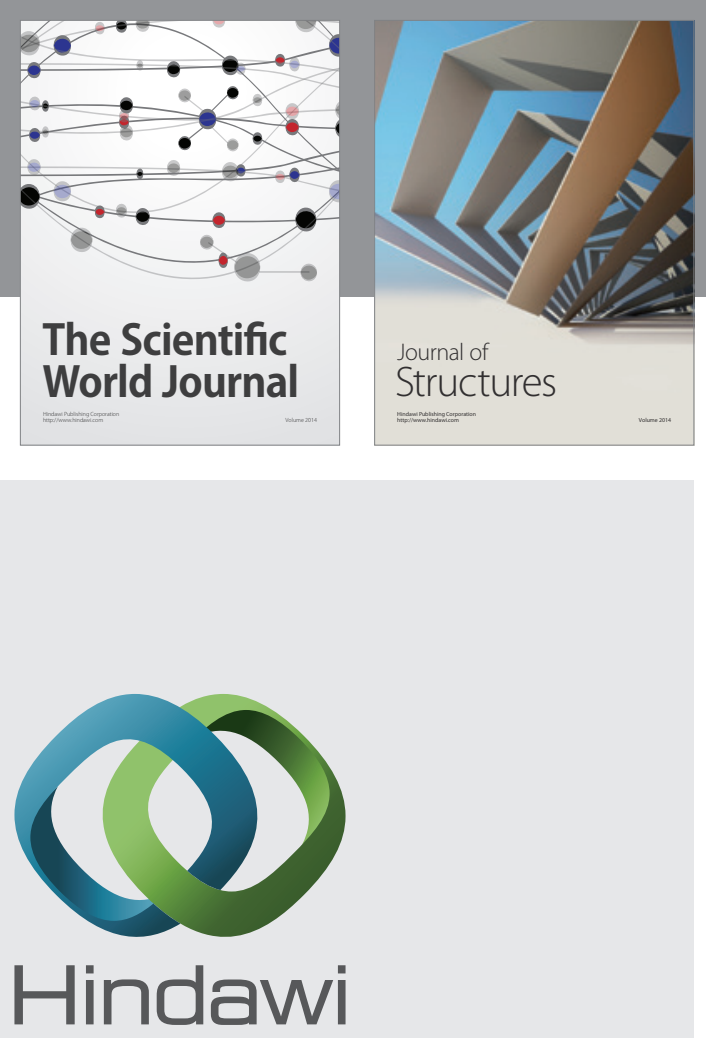

Submit your manuscripts at

http://www.hindawi.com
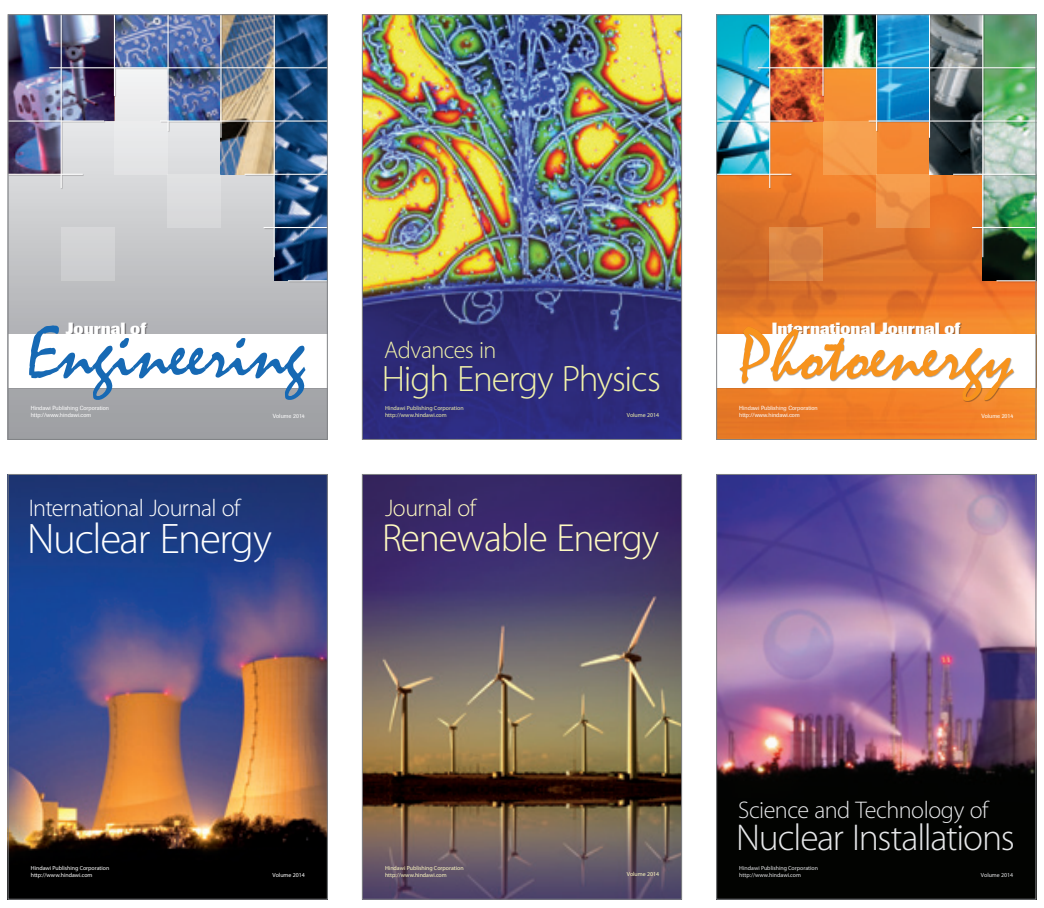
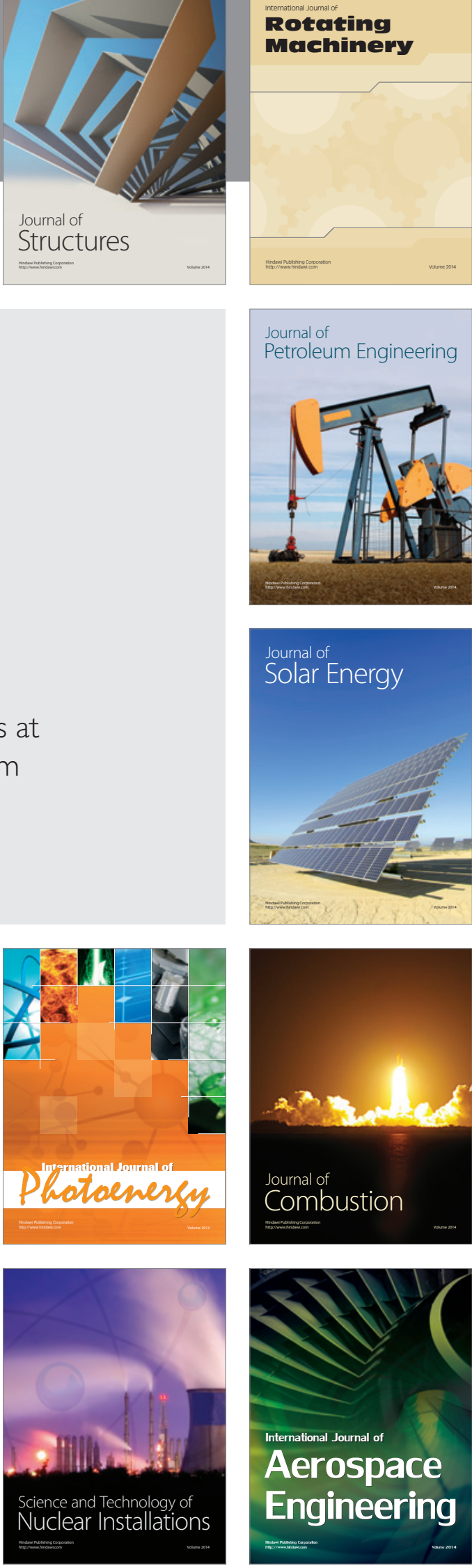